\title{
Hypogonadism in Male Infants and Adolescents: New Androgen Formulations
}

\author{
Laura Chioma Marco Cappa
}

Endocrinology Unit, University Pediatric Department, Bambino Gesù Children's Hospital, IRCCS, Rome, Italy

\section{Keywords}

Testosterone replacement therapy · Male hypogonadism ·

Pediatrics · Adolescence $\cdot$ New testosterone formulations

\begin{abstract}
Background: Male hypogonadism may be associated with micropenis and cryptorchidism in newborn, absent or incomplete pubertal development when it occurs during childhood. During puberty, androgen replacement therapy plays a pivotal role in subjects with hypogonadism to induce sexual maturation, growth acceleration, anabolic effects on fat-free mass growth increasing muscle strength, directly and indirectly on the attainment of peak bone mass in young men. Moreover, in newborns with congenital hypogonadism, androgen therapy could be effective to increase genital size. Summary: Testosterone replacement therapy (TRT) represents the cornerstone of the management of hypogonadism in boys. During puberty, replacement therapy needs to be modulated with gradual dosing increase to better mimic the physiologic pubertal development. Currently, intramuscular testosterone $(T)$ esters (in particular testosterone enanthate) and subcutaneous T pellets are the only formulations approved by the US Food and Drug Administration for delayed puberty, while no prepara-
\end{abstract}

tion is approved for long-term use in the adolescent age. Several new T formulations (as transdermal, nasal, subcutaneous, and oral formulation) are recently developed to improve the pharmacokinetic profile and to ease the administration route increasing patient compliance in adult males with hypogonadism. All these formulations are not approved for pediatric age, although some of them are used as "off-label" regimens. This special issue is aimed to illustrate new $T$ formulations and their potential role as replacement therapy in the pediatric population, as well as to highlight investigational areas to contribute to health care improvement in these patients. Key Messages: Despite the lack of evidence-based guidelines regarding the choice of $T$ formulation in the pediatric population, new formulations appear to have a potential role for TRT in adolescent age. They have been designed for adult age with a little flexibility of dosage, although a few formulations may be attractive for pubertal induction and penile enlargement thanks to their greater flexibility and easing of administration. On the other hand, long-acting and stable formulations could meet post-pubertal needs, increasing TRT compliance in a critical phase as the adolescent age. Further controlled, long-term safety, and efficacy studies for all these new $\mathrm{T}$ formulations within the pediatric population are needed.

(c) 2021 S. Karger AG, Basel karger@karger.com

www.karger.com/hrp

Karger'

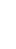

(C) 2021 S. Karger AG, Basel 


\section{Introduction}

Hypogonadism in males refers to a decrease in sperm and testosterone $(\mathrm{T})$ production. It may be related to gonadal failure (primary hypogonadism) or hypothalamuspituitary disease (secondary hypogonadism). Primary hypogonadism is characterized by low serum $\mathrm{T}$ and elevated FSH and LH levels (hypergonadotropic hypogonadism), while secondary hypogonadism presents both $\mathrm{T}$ and gonadotropin hormone deficiency (hypogonadotropic hypogonadism, $\mathrm{HoH}$ ).

Clinical features of hypogonadism may vary greatly, depending upon when this occurs. Congenital androgen defects during the first trimester of intrauterine time result in uncompleted virilization of male fetuses, while later decreased T production, during the third trimester in fetuses and the mini-puberty in newborns, is associated with small penis (so-called micropenis) and cryptorchidism. Lastly, when hypogonadism occurs during childhood or peri-pubertal time, it is associated with absent or incomplete pubertal development. Hypogonadism can also cause short- and long-term consequences such as secondary osteoporosis [1], increased risk for metabolic syndrome $[2,3]$, and depression with consequent impaired psychosexual health [4-6].

Both hypergonadotropic and hypogonadotropic forms of hypogonadism may be either due to congenital or acquired disease. The most frequent causes are summarized in Table 1.

Androgen replacement therapy should be aimed to reproduce the physiological effect of $\mathrm{T}$ on many different tissues and systems. In newborns with the absence of mini-puberty, a short-term therapy with androgens (both $\mathrm{T}$ and $5 a$-dihydrotestosterone) could be effective to correct micropenis [7-11]. In infants with $\mathrm{HoH}$, combined gonadotropin (FSH plus $\mathrm{LH}$ recombinant) or GnRH injective therapy seems to be able to restore the hormonal pathway of mini-puberty allowing the descent of retractile testis, as well as Sertoli and germ cell proliferation and initial maturation [12-15]. This suggests that early gonadotropin therapy may improve the fertility potential and the response to gonadotropin therapy during adolescence and adult life [15-17]. These therapies represent a valid alternative to androgens therapy, although they are more invasive, and their therapeutic use is beyond the scope of this review. During puberty, beyond inducing sexual maturation, androgens play an anabolic role on bone mass, both directly and through their conversion to estrogen by aromatase, contributing to the attainment of peak bone mass in young men $[18,19]$. Sex steroids are able to induce growth acceleration, defined also pubertal "spurt", thanks to their synergic effects on GH-IGF1 secretion, through estrogen conversion, and directly interacting with androgen receptor localized in the growth plate cartilage [20-22]. T has also anabolic effects on muscle mass and body composition [23-25]. Several studies have demonstrated the effects of testosterone replacement therapy (TRT) in hypogonadal men to increase fat-free mass, muscle strength, and to reduce fat mass [2, 25-27]. Finally, young men with untreated hypogonadism have lower HDL cholesterol levels and increased cardiometabolic risk, compared to healthy controls [28].

For all these reasons, $\mathrm{T}$ therapy represents the cornerstone of the management of hypogonadism in boys. Although testosterone enanthate (TE) and subcutaneous (SC) T pellets are the only formulations approved by the US Food and Drug Administration for adolescent males [29-31], a number of new formulations are currently used as "off-label" regimens. This report is aimed to illustrate new $\mathrm{T}$ formulations and their potential role as replacement therapy in newborn, child, and adolescent males with hypogonadism.

\section{Main Text}

The most common use of $\mathrm{T}$ therapy in childhood is related to pubertal induction in boys with constitutional delay in growth and puberty (CDGP), the most frequent and self-limited form of $\mathrm{HoH}$. In boys with delayed puberty, a short-term therapy with low-dose of $\mathrm{T}$ may be proposed as an alternative to expectant observation for psychological reason. Furthermore, it could be useful to differentiate CDGP to permanent $\mathrm{HoH}$, often indiscernible prior to the $\mathrm{T}$ therapy. In adolescents with persistent hypogonadism, TRT is a long-term therapy with the peculiarity of the need to be modulated with a gradual increase of the dose to mimic the physiological pubertal maturation.

Since mid-20th century, several $\mathrm{T}$ formulations have been developed to improve their pharmacokinetics and to reduce potential adverse effects. The first available formulations, introduced between 1940s and 1950s, included SC pellets and intramuscular (IM) injection of T esters (propionate, enanthate, and cypionate). Current TRT formulations and their pediatric dosing regimens are summarized in Table 2.

Pellets, available only in USA, UK, and Australia, are implanted subcutaneously every 3-6 months, requiring a 
Table 1. Classification of hypogonadism in males

Hypogonadotropic hypogonadism

Hypogonadotropic hypogonadism

Transient (costitutional delay in growth and puberty)

Congenital

Isolated (Kallmann syndrome, LHRH receptor mutation, congenital adrenal hypoplasia [DAX1 mutation], isolated LH deficiency, isolated FSH deficiency)

Multiple pituitary hormone deficiency (PROP1 mutation)

Syndrome associated (Prader-Willi, Laurence-Moon, and Bardet-Biedl syndrome)

Functional gonadotropin deficiency

Chronic systemic disease (cystic fibrosis, AIDS, chronic gastroenteric disease, chronic renal disease, sickle cell disease)

Malnutrition (eating disorders, intense physical exercise)

Associated with other endocrine diseases (hypothyroidism, diabetes mellitus, Cushing disease, hyperprolactinemia)

Acquired gonadotropin deficiency

CNS tumors and infiltrative causes (craniopharyngiomas, germinomas, hypothalamic and optic gliomas,

astrocytomas, Langerhans histiocytosis)

Post-CNS surgery or radiation therapy

Other causes: postinfectious lesion of CNS, head trauma, lymphocytic hypophysitis, congenital midline anomalies (as holoprosencephaly)

CNS, central nervous system.

Table 2. Current T replacement therapy with pediatric dosing regimens and relative advantage or disadvantage formulation

\begin{tabular}{|c|c|c|}
\hline Formulation & Commonly used regimens in pediatric population & Advantage/disadvantage \\
\hline $\begin{array}{l}\text { Subcutaneous T } \\
\text { pellets }\end{array}$ & $\begin{array}{l}\text { Puberty induction: ND } \\
\text { Adult dose: } 8-10 \mathrm{mg} / \mathrm{kg} \text { every } 6 \text { months [26] or } 150-450 \mathrm{mg} \text { every 3-6 } \\
\text { months [25] }\end{array}$ & $\begin{array}{l}\text { A: good compliance; well tolerated by adolescents } \\
\text { D: wide variability of serum T levels; need to repeat } \\
\text { surgical implantations }\end{array}$ \\
\hline $\begin{array}{l}\text { IM T esters (enanthate } \\
\text { and cypionate) }\end{array}$ & $\begin{array}{l}\text { Newborn micropenis: } 25 \mathrm{mg} \text { every } 3 \text { weeks for } 3 \text { months }[8,37] \\
\text { Pubertal induction: Starting dose of } 25-50 \mathrm{mg} \text { every } 4 \text { weeks for } 6 \text { months. } \\
\text { Titration scheme: Increase of } 50 \mathrm{mg} \text { every } 6-12 \text { months until the dose of } \\
150-200 \mathrm{mg} \text { every } 4 \text { weeks, then decrease interval to every } 2 \text { weeks as } \\
\text { adult dose [34-36] } \\
\text { Adult dose: } 150-200 \text { mg every } 2 \text { weeks [20] }\end{array}$ & $\begin{array}{l}\text { A: low cost, most clinical experience in childhood } \\
\text { D: nonphysiological serum T fluctuations, painful } \\
\text { injections, behavior disturbances; recurrent } \\
\text { physician office visits requirement }\end{array}$ \\
\hline Oral TU & $\begin{array}{l}\text { Pubertal induction: } 20-40 \mathrm{mg} \text { daily [42-44] } \\
\text { Adult dose: } 40-80 \mathrm{mg} \text { twice daily [20] }\end{array}$ & $\begin{array}{l}\text { A: painless administration } \\
\text { D: erratic oral bioavailability depending upon the } \\
\text { lipid content of meals; twice-daily administration }\end{array}$ \\
\hline Transdermal T patch & $\begin{array}{l}\text { Pubertal induction: } 2.5 \mathrm{mg} \text { for } 12 \mathrm{~h} \text { daily, or } 5 \mathrm{mg} \text { for } 8-12 \mathrm{~h} \text { daily } \\
\text { application for } 6 \mathrm{months}[45,46] \\
\text { Adult dose: } 5-10 \mathrm{mg} \text { over } 24 \mathrm{~h} \text { daily [20] }\end{array}$ & $\begin{array}{l}\text { A: painless administration, easy application } \\
\text { D: skin irritation, indivisible formulation }\end{array}$ \\
\hline
\end{tabular}

A, advantage; D, disadvantage; ND, no data.

minor surgical procedure for the implantation. This formulation was well tolerated when used in adolescent males, even if few cases have been described $[32,33]$. In addition, it was reported wide variability in circulating $\mathrm{T}$ levels, with excessively high serum $\mathrm{T}$ values for the early stage of puberty. No reports are available upon the use of pellets for pubertal induction.

Despite the limited number of prospective studies involving adolescent males [34, 35], IM TE is the most frequently used therapy for induction and progression of

\author{
Congenital \\ Klinefelter syndrome \\ Testicular steroid \\ biosynthetic defects \\ Sertoli-only syndrome \\ LH receptor mutation \\ Testicular dysgenesis \\ Anorchia/Vanishing testis \\ Acquired testicular failure \\ Chemotherapy \\ Testicular radiation therapy \\ Cryptorchidism \\ Testicular trauma, torsion \\ Orchitis \\ Orchiectomy
}

puberty in boys. Different regimens have been reported with a positive effect on pubertal maturation in boys with delayed puberty [36-39], while no data are available concerning titration schemes to adult $\mathrm{T}$ doses and long-term safety and efficacy. Some escalation schemes from pubertal induction to adulthood doses have been proposed [40-42]. During the neonatal period, short-term lowdose injective $\mathrm{T}$ esters therapy could also be used to increase penile size in hypogonadal boys [43,44], although a standardized dosing regimen has not been established. 
Table 3. New T formulations, adult dosage, pediatric application, and relative advantages or disadvantages

\begin{tabular}{|c|c|c|c|}
\hline Formulation & Adult dose & Pediatric use & Advantage/disadvantage \\
\hline $\begin{array}{l}\text { Transdermal gel } \\
(1 \% \text { or } 2 \%)\end{array}$ & $\begin{array}{l}\text { 1\% gel: } 50-100 \text { mg daily [20] } \\
2 \% \text { gel: } 40-70 \text { mg daily [20] }\end{array}$ & $\begin{array}{l}\text { Pubertal induction in delayed puberty: } \\
2 \% \text { gel } 10 \mathrm{mg} \text { daily for } 3 \text { months [48]. } \\
\text { Replacement therapy in boys with } \\
\text { hypogonadism: } 1 \% \text { gel } 0.5 \mathrm{~g} \text { up to } 5 \mathrm{~g} \\
\text { daily [53] }\end{array}$ & $\begin{array}{l}\text { A: extreme flexibility of dosing; self-application; painless } \\
\text { formulation; physiological pharmacokinetics; avoid of } \\
\text { hepatic first-pass metabolism; mild adverse effects; good } \\
\text { skin tolerability } \\
\text { D: adherence to daily formulation; unintentional drug } \\
\text { transference to other persons }\end{array}$ \\
\hline Nasal gel & $\begin{array}{l}11 \mathrm{mg} \text { (5.5 mg for each nostril) } \\
\text { twice or three-time daily [20] }\end{array}$ & ND & $\begin{array}{l}\text { A: high drug bioavailability; avoid of first-pass metabolism; } \\
\text { stable serum T profile; noninvasive, rapid and self- } \\
\text { application; mild local adverse effects } \\
\text { D: multiple daily formulation; limited availability of dosing }\end{array}$ \\
\hline $\begin{array}{l}\text { Oral TU soft } \\
\text { capsule }\end{array}$ & $\begin{array}{l}1 \text { capsule (equivalent to } 150 \mathrm{mg} \\
\text { of T unesterified) twice daily [55] }\end{array}$ & ND & $\begin{array}{l}\text { A: noninvasive formulation; mild within-day serum T } \\
\text { fluctuation } \\
\text { D: multiple daily formulation; mild gastrointestinal side } \\
\text { effects; requirement of minimum fat content in meals; } \\
\text { single adult dose availability }\end{array}$ \\
\hline SC T esters & 50-100 mg weekly $[20,66]$ & ND & $\begin{array}{l}\text { A: painless and self-administrated SC injections; avoid of } \\
\text { recurrent physician office visits; stable serum T profile } \\
\text { D: limited availability of dosing }\end{array}$ \\
\hline $\begin{array}{l}\text { Long-acting } \\
\text { injective TU }\end{array}$ & $\begin{array}{l}750 \mathrm{mg} \text { IM, followed by } 750 \mathrm{mg} \\
\text { at } 4 \text { week, then } 750 \mathrm{mg} \text { every } \\
10-14 \text { weeks [20] }\end{array}$ & ND & $\begin{array}{l}\text { A: prolonged IM reservoir with continuous release of T; } \\
\text { stable serum T levels; high adherence to long-term } \\
\text { administration } \\
\text { D: single adult dosage; long-term effect; local adverse } \\
\text { effects }\end{array}$ \\
\hline
\end{tabular}

A, advantage; D, disadvantage; ND, no data.

IM T therapy presents some pitfalls. Indeed, both enanthate and cypionate esters are unable to mimic the physiological T levels due to their pharmacokinetic profiles. $\mathrm{T}$ rises to supraphysiological concentrations a few days after injection, with a gradual decrease to subphysiological levels within the following 2-3 weeks [45]. Propionate ester is uncommonly used for hypogonadism treatment, due to its short-term formulation and wide $\mathrm{T}$ fluctuations. A possible inconvenience of $\mathrm{T}$ esters is related to IM injections and relative discomfort, although no specific data upon its influence on compliance are available.

Oral T undecanoate (TU) was developed in the 1980s to avoid the liver inactivation of earlier natural oral $\mathrm{T}$ formulation. It is absorbed into the lymphatic system, bypassing liver inactivation, even if oral bioavailability is unreliable depending upon the lipid content of meals [46, 47]. Some authors have reported oral TU use in pediatric population [48-50], although the short half-life and the requirement of multiple daily doses make it difficult to use in long-term replacement therapy.

Transdermal T patches introduced in the 1990s were designed for adult doses and cannot be divided. For this reason, their use in males during childhood and adolescence is extremely limited $[51,52]$.

From 2000s, novel T formulations have become available with the introduction of topical gels, oral soft gel, nasal preparation, SC depot, and a long-acting IM formulation. New $\mathrm{T}$ formulations, their relative advantages or disadvantages, and their possible use in the pediatric population are summarized in Table 3.

\section{Transdermal Gel Formulations}

T transdermal gel formulations represent an upcoming option for hormonal replacement therapy. Their appeal is related both to the daily self-administration, avoiding the injection discomfort, and to a more physiological pharmacokinetics. Population pharmacokinetic analysis has demonstrated that 1 or $2 \%$ hydroalcoholic gel application allows a rapid rise of serum $\mathrm{T}$ levels in hypogonadal males, reaching the steady-state level at the end of the first day [53]. Thereafter, serum T levels may undergo very small peak to trough fluctuations because $\mathrm{T}$ absorbed is likely stored as a skin reservoir and then slowly release 
to the circulation as a sustained release delivery system [53]. Gel formulations may provide therefore a more physiological TRT in hypogonadal males.

At present, gel formulations have been extensively studied in adults and are approved as TRT only in men with hypogonadism. Their pediatric experience is still limited, lacking randomized controlled trials.

Short-term induction therapy with gel formulation has been proposed in boys with CDGP, as a valid alternative to IM TE [54]. The advantages of gels consist in the noninvasive formulation and low-dose availability for a few of them with a minimum dose equivalent to about one-quarter to one-sixth of adult dosage, useful for a more physiological pubertal induction. In addition, transdermal absorption allows to avoid first-pass metabolism and potential hepatic toxicity of injected $\mathrm{T}$ formulations, as reported in some case reports regarding high dose selfadministration of anabolic androgen steroids in bodybuilders [55-57]. Therefore, transdermal gel $\mathrm{T}$ may be used also in subjects with hepatic dysfunction [58].

Few data are available on gel formulations for longterm TRT in boys with hypogonadism. Rogol et al. [59] evaluated the safety and clinical outcomes of 6-month treatment with $\mathrm{T}$ gel $1 \%$ therapy in adolescents with hypogonadism related to Klinefelter syndrome (21 subjects) or anorchia (8 subjects). The authors had retrospectively analyzed data from a multicenter open-label observational study carried out in adolescent boys with primary or secondary hypogonadism, or with CDGP treated with a starting dose of $0.5 \mathrm{~g}$ T gel (Androgen 1\%; AbbVie, North Chicago, IL, USA) once daily with a dose titration up to $5.0 \mathrm{~g}$ daily, based on investigator clinical judgment. The authors had demonstrated as the gel TRT was able to increase serum $\mathrm{T}$ and relative metabolites to normal agematched values, with mild adverse effects like cough, acne, and headache. No significant safety concerns were reported, while treatment compliance was suboptimal (72\%) [59]. In a larger retrospective analysis [60], gel formulation was administrated in 104 boys with Klinefelter syndrome, with a dose titration to reach high-normal serum $\mathrm{T}$ levels. The study aim was to investigate the safety and tolerability of a prolonged TRT (average of TRT duration was almost 24 months) in these subjects followed up to 5 years. The authors reported no severe adverse event associated with $\mathrm{T}$ therapy. In particular, neither behavior modification nor deep vein thrombosis was reported, while a small percentage $(8 \%)$ of patients complained of acne-requiring medical treatment. The gel administration did not suppress gonadotropin levels in the study population, suggesting the more physiological

New Androgen Formulations in Pediatric and Adolescent Populations pharmacokinetics of topical $\mathrm{T}$ formulations. It should be noted that the majority of boys with Klinefelter syndrome presents a spontaneous puberty onset with a subsequent gonadal failure, often requiring a TRT from mid puberty onward. For this reason, T supplementation appears to be easier to set at the appropriate dosage in adolescents with Klinefelter syndrome than in other boys with hypogonadism. During the extended observation period, the gel formulation was well tolerated, and patient compliance was high, despite a small proportion of the subjects reported to have forgotten to apply the gel on occasion [60].

The advantages of gel formulation for long-term TRT in adolescents are similar to those in adulthood and include the flexibility of dosing, the easy self-application, and the small number of adverse events reported [26]. The availability of very low dosing could suggest gel formulation particularly useful for newborn micropenis treatment, although no data are available in these patients. A potential disadvantage may consist in the daily administration and its compliance in a critical phase of life as the adolescent age. An extensive counseling of patients and their parents on TRT benefits and the active involvement of patients in the management of $\mathrm{T}$ therapy may increase subject motivation favoring higher TRT compliance. Finally, gel preparations may lead an unintentional $\mathrm{T}$ transference to patients' family members. The potential risk of secondary exposure to androgens could represent an important disadvantage of transdermal gels in adolescents with behavioral difficulties as Klinefelter syndrome population.

\section{New Oral TU Soft Capsule}

Recently, a phase 3 clinical trial has investigated a new formulation of oral TU dissolved in a combination of lipids and hydrophilic surfactant, encapsulated in soft gelatin capsules in 18-65 years man with hypogonadism [61]. This formulation enables TU solubilization and consequently its absorption with meals without requiring high-fat content [62]. No clinically significant difference in serum $\mathrm{T}$ levels was observed among different meal fat compositions. Twice-daily oral TU administration immediately before a breakfast and dinner meal was demonstrated to be effective to restore eugonadal T levels in hypogonadal men, avoiding excessive peak concentrations. This dosing regimen has been adopted because plasma $\mathrm{T}$ concentration decline under eugonadal $\mathrm{T}$ range about $8-12 \mathrm{~h}$ after oral TU dose, with a mild within-day fluctuation. The overall safety profile was similar to oth- 
er approved TRT products. Gastrointestinal side effects were reported (nausea, diarrhea, and burping), but these were minor in severity, transient, and did not request discontinuation of oral TU therapy [61].

At present, no studies are available on the pediatric population. In our opinion, this novel formulation presents some weaknesses as long-term TRT in adolescents, since twice-daily oral dosing could reduce subject adherence to the therapy. In addition, oral administration with food requires a minimum fat content $(15 \mathrm{~g})$ in breakfast meals not always guaranteed in all types of diets, as sweet breakfast of the Mediterranean diet. Finally, the availability of a single dosage (150 mg of unesterified T equivalents for capsule) equal to adult TRT dose reduces its use only in postpubertal boys with hypogonadism after completing the pubertal induction.

\section{Nasal T Gel}

In the last years, the intranasal route has been increasingly investigated for systemic drug delivery thanks to the high permeability and high drug bioavailability of the nasal mucosa, avoiding first-pass metabolism [63, 64]. Nasal $\mathrm{T}$ gel formulation has been also explored to overcome some undesired properties of transdermal gel formulations, as skin absorption or irritation problems and unintentional $\mathrm{T}$ transference to patients' family members. Multiple daily doses were required to achieve appropriate $\mathrm{T}$ circulating levels. In addition, the intranasal route seems to be a simple, noninvasive, safe, and rapid administration via, requiring only a few seconds per day for the drug assumption [65].

A multicenter phase 3 randomized open-label study showed that $\mathrm{T}$ nasal gel restores $\mathrm{T}$ levels to eugonadal ranges in males aged 18-80 years with hypogonadism [66]. A 4.5\% T gel was administrated from a nonpressurized, manual pump dispenser with a specific nasal applicator. The single dose was $125 \mu \mathrm{L}$ (equivalent to $5.5 \mathrm{mg}$ of $\mathrm{T}$ ) for each nostril (total dose $11 \mathrm{mg}$ of T). After each nasal dose, it was observed that a short-acting peak of plasma $\mathrm{T}$ level, declining to baseline values about $2-4 \mathrm{~h}$ after administration. Peak values were consistently below safety upper-limit ranges, while the peaks-and-troughs serum $\mathrm{T}$ profile did not appear to have a negative impact on sexual function and energy-related symptoms. Twice daily and 3-time daily nasal gel administration were well tolerated, restoring T levels into eugonadal ranges in the majority of study subjects. Active allergic rhinitis or the use of a symptomatic decongestant drug did not affect the absorption and bioavailability of $\mathrm{T}$ from nasal formulation [67]. The short-acting pharmacokinetic property of nasal gel seems to be responsible of a more physiological T release, allowing the maintenance of gonadotropin levels within normal limits and preserving a normal spermatogenesis in nearly all men with hypogonadism observed [68].

The most commonly reported adverse effects were of mild severity with low incidence in both dosing regimens. They were related to local nasal side effects, as nasopharyngitis, rhinorrhea, or epistaxis. A recent retrospective cross-sectional analysis reported no cases of polycythemia, the most frequent adverse effect of TRT, in patients treated with nasal gel therapy [69].

The nasal gel formulation was well tolerated by most subjects. Nearly half of interviewed men remarked the beneficial property of not touching the gel preparation that probably outweighs the necessity of multiple daily dosing regimens [66].

Nasal gel T is approved as TRT in men with hypogonadism over 18 years, while its safety and effectiveness have not been established in the pediatric population. The potential use of nasal gel may be promising also in adolescents with hypogonadism, although the limited availability of dose titration makes its role less usable for pubertal induction.

\section{SC Formulation}

From the beginning of the 2000s, some preliminary reports have investigated weekly SC T administration as an alternative route for TRT to currently available options [70, 71]. More recent phases II and III pharmacokinetic studies have demonstrated that administration of TE in oil SC formulations through an autoinjector device was effective to restore physiological $\mathrm{T}$ levels in patients with hypogonadism $[72,73]$. The serum $\mathrm{T}$ level achieves normal values within a few hours after the first dose, with a lower peak to trough variability compared to IM TE. SC administration of TE appeared to be safe and welltolerated by subjects. A different study has investigated the use of T cypionate SC formulation as TRT in female-to-male transgender patients [74]. Weekly SC self-administrated $\mathrm{T}$ cypionate in cottonseed oil solution resulted to be effective, safe, and well accepted by transgender subjects, preferring SC to IM formulations. No serious local reactions at the injection sites were reported in all of the abovementioned studies [72, 73].

No data are available regarding the use of SC T formulation in the pediatric population. Weekly SC preparations 
appear to have a potential role in TRT in adolescent age, thanks to the painless and self-administrated SC injections, avoiding recurrent physician office visits. In addition, the availability of different dosages of SC T may be useful for dose titration during pubertal induction therapy.

\section{Long-Acting IM Formulation}

From the beginning of 2000s, a novel injectable TU formulation was available. The semisynthetic androgen TU is dissolved in castor oil solvent and benzyl benzoate as cosolvent agent. This component combination provides a prolonged IM reservoir, thus enabling a continuous release of $\mathrm{T}$ from the ester into the bloodstream. Long-acting IM TU is administered with a 6-week interval for the first 2 injections (loading dose), and then every 10-14 weeks according to pre-injection serum $\mathrm{T}$ levels. This dosing regimen results in a significant reduction of injection frequency (4-5 per year) with a consequent increase in patient compliance. In addition, this novel injective formulation does not result in supraphysiological serum $\mathrm{T}$ levels. Indeed, pharmacokinetic analysis revealed stable $\mathrm{T}$ levels within the normal range, with a steady peak to trough profile after the third injection [75-78]. IM TU was approved by Food and Drug Administration in 2014 as a safe and effective form of TRT for adult males with hypogonadism. Pulmonary oil microembolism has been reported as a rare adverse event of IM TU formulations, related to its castor oil compound. A recent postmarketing safety analysis demonstrated that pulmonary oil microembolism events related to IM TU therapy were rare and resolved quickly without medical intervention in the majority of cases reported. The most severe cases were associated with nonlabeled adherent injection techniques or dosing errors [79].

No data are available on IM TU use in children. Its use seems to be limited in pubertal age due to only adult dosage availability and its long-acting release. On the contrary, this formulation could be useful as long-term TRT in adolescents with hypogonadism after the pubertal induction period.

\section{Conclusion}

New T formulations are demonstrated to be safe, effective, and well accepted as TRT in males with hypogonadism. Unfortunately, these formulations are approved only for adults due to the lack of randomized controlled trials in the pediatric population. However emerging data support safety, efficacy, and high compliance of transdermal formulation for TRT also in adolescent age $[59,60]$. At present, pubertal induction is typically enabled with IM T esters, given the major clinical experience with this preparation, and then switched to newer formulation with "offlabel" regimens once adult dosing is reached. Many fewer data are available upon T use during mini-puberty in newborns with micropenis and hypogonadism, with only a few schemes therapy based on expert opinions [8].

Despite no evidence-based guidelines regarding pubertal induction dosing regimens or optimal $\mathrm{T}$ formulation, TRT should be individualized to the patient's age and needs. It would be desirable to use a slow titration dosing regimen during pubertal induction up to adult dosage, when adult height is reached. In this direction, the flexibility of dosing and easing of administration of some formulations, as a few transdermal gels or SC TE, could make them attractive for pubertal induction in adolescent age. In this respect, it should be noted that the majority of new $\mathrm{T}$ formulation may be used in pediatric population only from mid-puberty onward, due to their little flexibility of dosing. On the other hand, long-acting and stable formulations, as IM UT, could meet post-pubertal needs of the adolescent population, increasing TRT compliance in a critical phase for acceptance of chronic diseases. Finally, nasal gel and oral soft capsule daily formulation may represent a good painless and noninvasive choice for after-pubertal long-term TRT of male hypogonadism also in children. Further controlled, long-term safety, and efficacy studies for all these new $\mathrm{T}$ formulations on the pediatric population are needed.

\section{Conflict of Interest Statement}

The authors have no conflicts of interest to declare.

\section{Funding Sources}

This research did not receive any specific grant from any funding agency in the public, commercial, or not-for-profit sector.

\section{Author Contributions}

All authors contributed to the study's conception and design. Material preparation, data collection, and analysis were performed by L.C. and M.C. The first draft of the manuscript was written by L.C. M.C. reviewed and commented the manuscript. All authors read and approved the final manuscript. 


\section{References}

1 Golds G, Houdek D, Arnason T. Male hypogonadism and osteoporosis: the effects, clinical consequences, and treatment of testosterone deficiency in bone health. Int J Endocrinol. 2017;2017:4602129.

2 Rastrelli G, Filippi S, Sforza A, Maggi M, Corona $\mathrm{G}$. Metabolic syndrome in male hypogonadism. Front Horm Res. 2018;49:131-55.

3 Dwyer AA, Quinton R. The metabolic syndrome in central hypogonadotrophic hypogonadism. Front Horm Res. 2018;49:156-69.

4 Varimo T, Hero M, Laitinen EM, Sintonen H, Raivio T. Health-related quality of life in male patients with congenital hypogonadotropic hypogonadism. Clin Endocrinol. 2015 Jul; 83(1):141-3.

5 Day FR, Elks CE, Murray A, Ong KK, Perry JR. Puberty timing associated with diabetes, cardiovascular disease and also diverse health outcomes in men and women: the UK Biobank study. Sci Rep. 2015 Jun 18;5:11208.

6 Dwyer AA, Quinton R, Pitteloud N, Morin D. Psychosexual development in men with congenital hypogonadotropic hypogonadism on long-term treatment: a mixed methods study. Sex Med. 2015 Mar;3(1):32-41.

7 Bin-Abbas B, Conte FA, Grumbach MM, Kaplan SL. Congenital hypogonadotropic hypogonadism and micropenis: effect of testosterone treatment on adult penile size why sex reversal is not indicated. J Pediatr. 1999 May 134(5):579-83.

8 Hatipoğlu N, Kurtoğlu S. Micropenis: etiology, diagnosis and treatment approaches. J Clin Res Pediatr Endocrinol. 2013;5(4):217-23.

9 Howard SR, Dunkel L. Management of hypogonadism from birth to adolescence. Best Pract Res Clin Endocrinol Metab. 2018 Aug; 32(4):355-72.

10 Young J, Xu C, Papadakis GE, Acierno JS, Maione L, Hietamäki J, et al. Clinical management of congenital hypogonadotropic hypogonadism. Endocr Rev. 2019 Apr 1;40(2): 669-710.

11 Bizzarri C, Cappa M. Ontogeny of hypothalamus-pituitary gonadal axis and minipuberty: an ongoing debate? Front Endocrinol. 2020 Apr 7;11:187.

12 Main KM, Schmidt IM, Toppari J, Skakkebaek NE. Early postnatal treatment of hypogonadotropic hypogonadism with recombinant human FSH and LH. Eur J Endocrinol. 2002 Jan;146(1):75-9.

13 Lambert AS, Bougneres P. Growth and descent of the testes in infants with hypogonadotropic hypogonadism receiving subcutaneous gonadotropin infusion. Int J Pediatr Endocrinol. 2016;2016:13.

14 Papadimitriou DT, Chrysis D, Nyktari G, Zoupanos G, Liakou E, Papadimitriou A, et al. Replacement of male mini-puberty. J Endocr Soc 2019 May 9;3(7):1275-82.

15 Boehm U, Bouloux PM, Dattani MT, de Roux N, Dodé C, Dunkel L, et al. Expert consensus document: European consensus statement on congenital hypogonadotropic hypogonadism - pathogenesis, diagnosis and treatment. Nat Rev Endocrinol. 2015 Sep;11(9):547-64.

16 Bouvattier C, Maione L, Bouligand J, Dode 区 C, Guiochon-Mantel A, Young J. Neonatal gonadotropin therapy in male congenital hypogonadotropic hypogonadism. Nat Rev Endocrinol. 2011 Oct 18;8(3):172-82.

17 Kohva E, Huopio H, Hero M, Miettinen PJ, Vaaralahti K, Sidoroff V, et al. Recombinant human FSH treatment outcomes in five boys with severe congenital hypogonadotropic hypogonadism. J Endocr Soc. 2018 Oct 15;2(12): 1345-56.

18 Vandenput L, Ohlsson C. Estrogens as regulators of bone health in men. Nat Rev Endocrinol. 2009 Aug;5(8):437-43.

19 Mohamad NV, Soelaiman IN, Chin KY. A concise review of testosterone and bone health. Clin Interv Aging. 2016;11:1317-24.

20 Perry RJ, Farquharson C, Ahmed SF. The role of sex steroids in controlling pubertal growth. Clin Endocrinol. 2008 Jan;68(1):4-15.

21 Birzniece V, Ho KKY. Sex steroids and the $\mathrm{GH}$ axis: implications for the management of hypopituitarism. Best Pract Res Clin Endocrinol Metab. 2017 Feb;31(1):59-69.

22 Nilsson O, Chrysis D, Pajulo O, Boman A, Holst M, Rubinstein J, et al. Localization of estrogen receptors-alpha and -beta and androgen receptor in the human growth plate at different pubertal stages. J Endocrinol. 2003 May;177(2):319-26.

23 Welle S, Jozefowicz R, Forbes G, Griggs RC. Effect of testosterone on metabolic rate and body composition in normal men and men with muscular dystrophy. J Clin Endocrinol Metab. 1992 Feb;74(2):332-5.

24 Nielsen TL, Hagen C, Wraae K, Brixen K, Petersen PH, Haug E, et al. Visceral and subcutaneous adipose tissue assessed by magnetic resonance imaging in relation to circulating androgens, sex hormone-binding globulin, and luteinizing hormone in young men. J Clin Endocrinol Metab. 2007 Jul;92(7):2696-705.

25 Chasland LC, Knuiman MW, Divitini ML, Murray K, Handelsman DJ, Flicker L, et al. Higher circulating androgens and higher physical activity levels are associated with less central adiposity and lower risk of cardiovascular death in older men. Clin Endocrinol. 2019 Feb;90(2):375-83.

26 Bhasin S, Brito JP, Cunningham GR, Hayes FJ, Hodis HN, Matsumoto AM, et al. Testosterone therapy in men with hypogonadism: an endocrine society clinical practice guideline. J Clin Endocrinol Metab. 2018 May 1; 103(5):1715-44.

27 Dimitriadis GK, Randeva HS, Aftab S, Ali A, Hattersley JG, Pandey S, et al. Metabolic phenotype of male obesity-related secondary hypogonadism pre-replacement and post-replacement therapy with intra-muscular testosterone undecanoate therapy. Endocrine. 2018 Apr;60(1):175-84.
28 Sonmez A, Haymana C, Bolu E, Aydogdu A, Tapan S, Serdar M, et al. Metabolic syndrome and the effect of testosterone treatment in young men with congenital hypogonadotropic hypogonadism. Eur J Endocrinol. 2011 May;164(5):759-64.

29 US Food and Drug Administration. FDA briefing document for the discussion of issues related to the potential evaluation of efficacy and safety of testosterone replacement therapy in male boys with hypogonadism due to genetic or structural etiologies [FDA briefing document, Pediatric Advisory Committee]. Rockville, MD: US FDA; 2019.

30 Endo Pharmaceuticals Solutions Inc. Delatestryl (testosterone enanthate injection, USP) [prescribing information]. Malvern, PA: Endo Pharmaceuticals Solutions Inc.; 2016.

31 Endo Pharmaceuticals, Inc. TESTOPEL (testosterone pellets) C-III [prescribing information]. Malvern, PA: Endo Pharmaceuticals, Inc.; 2018.

32 Zacharin MR, Warne GL. Treatment of hypogonadal adolescent boys with long acting subcutaneous testosterone pellets. Arch Dis Child. 1997 Jun;76(6):495-9.

33 Moskovic DJ, Freundlich RE, Yazdani P, Lipshultz LI, Khera M. Subcutaneous implantable testosterone pellets overcome noncompliance in adolescents with Klinefelter syndrome. J Androl. 2012 Jul-Aug;33(4):570-3.

34 Soliman AT, Khadir MM, Asfour M. Testosterone treatment in adolescent boys with constitutional delay of growth and development. Metabolism. 1995 Aug;44(8):1013-5.

35 Rosenfeld RG, Northcraft GB, Hintz RL. A prospective, randomized study of testosterone treatment of constitutional delay of growth and development in male adolescents. Pediatrics. 1982 Jun;69(6):681-7.

36 Richman RA, Kirsch LR. Testosterone treatment in adolescent boys with constitutional delay in growth and development. N Engl J Med. 1988 Dec 15;319(24):1563-7.

37 Bergada I, Bergada C. Long term treatment with low dose testosterone in constitutional delay of growth and puberty: effect on bone age maturation and pubertal progression. J Pediatr Endocrinol Metab. 1995 Apr-Jun;8(2):117-22.

38 Wilson DM, Kei J, Hintz RL, Rosenfeld RG. Effects of testosterone therapy for pubertal delay. Am J Dis Child. 1988 Jan;142(1):96-9.

39 Giri D, Patil P, Blair J, Dharmaraj P, Ramakrishnan $\mathrm{R}$, Das $\mathrm{U}$, et al. Testosterone therapy improves the first year height velocity in adolescent boys with constitutional delay of growth and puberty. Int J Endocrinol Metab. 2017 Apr;15(2):e42311.

40 Palmert MR, Dunkel L. Clinical practice. Delayed puberty. N Engl J Med. 2012 Feb 2; 366(5):443-53.

41 Bertelloni S, Baroncelli GI, Garofalo P, Cianfarani S. Androgen therapy in hypogonadal adolescent males. Horm Res Paediatr. 2010; 74(4):292-6. 
42 Dunkel L, Quinton R. Transition in endocrinology: induction of puberty. Eur J Endocrinol. 2014 Jun;170(6):R229-39.

43 Guthrie RD, Smith DW, Graham CB. Testosterone treatment for micropenis during early childhood. J Pediatr. 1973 Aug;83(2):247-52.

44 Main KM, Schmidt IM, Skakkebaek NE. A possible role for reproductive hormones in newborn boys: progressive hypogonadism without the postnatal testosterone peak. J Clin Endocrinol Metab. 2000 Dec;85(12):4905-7.

45 Shoskes JJ, Wilson MK, Spinner ML. Pharmacology of testosterone replacement therapy preparations. Transl Androl Urol. 2016 Dec; 5(6):834-43.

46 Schnabel PG, Bagchus W, Lass H, Thomsen T, Geurts TB. The effect of food composition on serum testosterone levels after oral administration of Andriol Testocaps. Clin Endocrinol. 2007 Apr;66(4):579-85.

47 Barbonetti A, D’Andrea S, Francavilla S. Testosterone replacement therapy. Andrology. 2020 Nov;8(6):1551-66.

48 Lawaetz JG, Hagen CP, Mieritz MG, Blomberg Jensen M, Petersen JH, Juul A. Evaluation of 451 Danish boys with delayed puberty: diagnostic use of a new puberty nomogram and effects of oral testosterone therapy. J Clin Endocrinol Metab. 2015 Apr;100(4):1376-85.

49 Albanese A, Kewley GD, Long A, Pearl KN, Robins DG, Stanhope R. Oral treatment for constitutional delay of growth and puberty in boys: a randomised trial of an anabolic steroid or testosterone undecanoate. Arch Dis Child. 1994 Oct; 71(4):315-7.

50 Ahmed SF, Tucker P, Mayo A, Wallace AM, Hughes IA. Randomized, crossover comparison study of the short-term effect of oral testosterone undecanoate and intramuscular testosterone depot on linear growth and serum bone alkaline phosphatase. J Pediatr Endocrinol Metab. 2004 Jul;17(7):941-50.

51 Mayo A, Macintyre H, Wallace AM, Ahmed SF. Transdermal testosterone application: pharmacokinetics and effects on pubertal status, short-term growth, and bone turnover. J Clin Endocrinol Metab. 2004 Feb;89(2):681-7.

52 De Sanctis V, Vullo C, Urso L, Rigolin F, Cavallini $\mathrm{A}$, Caramelli $\mathrm{K}$, et al. Clinical experience using the androderm testosterone transdermal system in hypogonadal adolescents and young men with beta-thalassemia major. J Pediatr Endocrinol Metab. 1998;11(Suppl 3):891-900.

53 Wang C, Berman N, Longstreth JA, Chuapoco B, Hull L, Steiner B, et al. Pharmacokinetics of transdermal testosterone gel in hypogonadal men: application of gel at one site versus four sites: a General Clinical Research Center Study. J Clin Endocrinol Metab. 2000 Mar; 85(3):964-9.

54 Chioma L, Papucci G, Fintini D, Cappa M. Use of testosterone gel compared to intramuscular formulation for puberty induction in males with constitutional delay of growth and puberty: a preliminary study. J Endocrinol Invest. $2018 \mathrm{Feb}$;41(2):259-63.
55 Stimac D, Milić S, Dintinjana RD, Kovac D, Ristić S. Androgenic/anabolic steroid-induced toxic hepatitis. J Clin Gastroenterol. 2002 Oct;35(4):350-2.

56 Pagonis TA, Koukoulis GN, Hadjichristodoulou CS, Toli PN, Angelopoulos NV. Multivitamins and phospholipids complex protects the hepatic cells from androgenic-anabolic-steroids-induced toxicity. Clin Toxicol 2008 Jan;46(1):57-66.

57 Solbach P, Potthoff A, Raatschen HJ, Soudah B, Lehmann U, Schneider A, et al. Testosterone-receptor positive hepatocellular carcinoma in a 29-year old bodybuilder with a history of anabolic androgenic steroid abuse: a case report. BMC Gastroenterol. 2015 May 20;15:60.

58 Contreras MF, Raisingani M, Prasad K, Franklin B, Shah B. Transdermal testosterone gel for induction and continuation of puberty in adolescent boys with hepatic dysfunction. J Pediatr Endocrinol Metab. 2017 Jan 1;30(1): 105-9.

59 Rogol AD, Swerdloff RS, Reiter EO, Ross JL, ZumBrunnen TL, Pratt GA, et al. A multicenter, open-label, observational study of testosterone gel (1\%) in the treatment of adolescent boys with klinefelter syndrome or anorchia. J Adolesc Health. 2014 Jan;54(1): $20-5$.

60 Mehta A, Clearman T, Paduch DA. Safety and efficacy of testosterone replacement therapy in adolescents with Klinefelter syndrome. J Urol. 2014 May;191(5 Suppl 1):1527-31.

61 Swerdloff RS, Wang C, White WB, Kaminetsky J, Gittelman MC, Longstreth JA, et al. A new oral testosterone undecanoate formulation restores testosterone to normal concentrations in hypogonadal men. J Clin Endocrinol Metab. 2020 Aug 1;105(8):2515-31.

62 Yin A, Alfadhli E, Htun M, Dudley R, Faulkner $\mathrm{S}$, Hull L, et al. Dietary fat modulates the testosterone pharmacokinetics of a new selfemulsifying formulation of oral testosterone undecanoate in hypogonadal men. J Androl. 2012 Nov-Dec;33(6):1282-90.

63 Mattern C, Hoffmann C, Morley JE, Badiu C. Testosterone supplementation for hypogonadal men by the nasal route. Aging Male. 2008 Dec;11(4):171-8.

64 Banks WA, Morley JE, Niehoff ML, Mattern C. Delivery of testosterone to the brain by intranasal administration: comparison to intravenous testosterone. J Drug Target. 2009 Feb; 17(2):91-7.

65 Pires A, Fortuna A, Alves G, Falcão A. Intranasal drug delivery: how, why and what for? J Pharm Pharm Sci. 2009;12(3):288-311.

66 Rogol AD, Tkachenko N, Bryson N. Natesto ${ }^{\mathrm{mx}}$, a novel testosterone nasal gel, normalizes androgen levels in hypogonadal men. Andrology. 2016 Jan;4(1):46-54

67 Rogol AD, Tkachenko N, Badorrek P, Hohlfeld JM, Bryson N. Phase 1 pharmacokinetics and phase 3 efficacy of testosterone nasal gel in subjects with seasonal allergies. Can Urol Assoc J. 2018 Jul;12(7):E349-56.
68 Ramasamy R, Masterson TA, Best JC, Bitran $\mathrm{J}$, Ibrahim E, Molina M, et al. Effect of natesto on reproductive hormones, semen parameters and hypogonadal symptoms: a single center, open label, single arm trial. J Urol. 2020 Sep;204(3):557-63.

69 Best JC, Gonzalez D, Masterson TA, Blachman-Braun R, Pai R, Ramasamy R. A crosssectional comparison of secondary polycythemia in testosterone-deficient men treated with nasal testosterone gel vs. intramuscular testosterone cypionate. Can Urol Assoc J. $2021 \mathrm{Feb} ; 15(2): E 118-E 22$.

70 Al-Futaisi AM, Al-Zakwani IS, Almahrezi AM, Morris D. Subcutaneous administration of testosterone. A pilot study report. Saudi Med J. 2006 Dec;27(12):1843-6.

71 Olson J, Schrager SM, Clark LF, Dunlap SL, Belzer M. Subcutaneous testosterone: an effective delivery mechanism for masculinizing young transgender men. LGBT Health. 2014 Sep;1(3):165-7.

72 Kaminetsky J, Jaffe JS, Swerdloff RS. Pharmacokinetic profile of subcutaneous testosterone enanthate delivered via a novel, prefilled single-use autoinjector: a phase II study. Sex Med. 2015 Dec;3(4):269-79.

73 Gittelman M, Jaffe JS, Kaminetsky JC. Safety of a new subcutaneous testosterone enanthate auto-injector: results of a 26-week study. J Sex Med. 2019 Nov;16(11):1741-8.

74 Spratt DI, Stewart II, Savage C, Craig W, Spack NP, Chandler DW, et al. Subcutaneous injection of testosterone is an effective and preferred alternative to intramuscular injection: demonstration in female-to-male transgender patients. J Clin Endocrinol Metab. 2017 Jul 1;102(7):2349-55.

75 von Eckardstein S, Nieschlag E. Treatment of male hypogonadism with testosterone undecanoate injected at extended intervals of 12 weeks: a phase II study. J Androl. 2002 MayJun;23(3):419-25.

76 Schubert M, Minnemann T, Hubler D, Rouskova $\mathrm{D}$, Christoph $\mathrm{A}$, Oettel $\mathrm{M}$, et al. Intramuscular testosterone undecanoate: pharmacokinetic aspects of a novel testosterone formulation during long-term treatment of men with hypogonadism. J Clin Endocrinol Metab. 2004 Nov;89(11):5429-34.

77 Harle L, Basaria S, Dobs AS. Nebido: a longacting injectable testosterone for the treatment of male hypogonadism. Expert Opin Pharmacother. 2005 Aug;6(10):1751-9.

78 Saad F, Kamischke A, Yassin A, Zitzmann M, Schubert M, Jockenhel F, et al. More than eight years' hands-on experience with the novel long-acting parenteral testosterone undecanoate. Asian J Androl. 2007 May;9(3): 291-7.

79 Pastuszak AW, Hu Y, Freid JD. Occurrence of pulmonary oil microembolism after testosterone undecanoate injection: a postmarketing safety analysis. Sex Med. 2020 Jun;8(2):23742. 